recording (derived from saturation monitor) was unreliable; reading low during exercise compared to ECG-derived HR.

Conclusions This small study confirms the Innocor device can produce measures of $\mathrm{VO}_{2} \max$ comparable $(95 \%$ confidence interval) with standard calibrated exercise systems in CF patients with mild to moderate lung disease. We found the method for Innocor to derive HR (pulse oximetry) was not reliable compared to reference ECG especially during heavy exercise. We were subsequently able to overcome this problem by interfacing the Innocor device with a separate electrocardiographic heart rate monitor.

\section{P208 ASSESSMENT OF CURVILINEARITY (CURV) AND PHASE III ANALYSIS OF MULTIPLE BREATH WASHOUT (MBW)}

${ }^{1} \mathrm{SJ}$ Inving, ${ }^{2} \mathrm{~A}$ Bush. ${ }^{1}$ Royal Brompton and Harefield NHS Foundation Trust, London, UK; ${ }^{2}$ Imperial College, London, UK

\subsection{6/thoraxjnl-2014-206260.337}

Introduction and Hypothesis In cystic fibrosis (CF), but not in PCD (Am J Respir Crit Care Med. 2013;188:545-549), lung clearance index (LCI) and spirometry are correlated. The difference may be related to differences in small airway disease. To explore this further, the novel MBW analyses Curv, $\mathrm{S}_{\text {cond* }}$ and $\mathrm{S}_{\text {acin" }}$ were calculated in PCD and CF (Eur Respir J. 2013;42 (suppl 2):380-388). Curv assesses specific ventilation inhomogeneity calculated as the ratio of the slope of the first half to the second half of the washout, and unlike LCI is not sensitive to deadspace effects. $S_{\text {cond }}$ and $S_{\text {acin }}$ are not useful in severe obstructive lung disease; $S_{\text {cond" }}$ and $S_{\text {acin" }}$ are recalculations corresponding respectively to $\mathrm{VI}$ in the conducting airways and the acinar region. $\left(\mathrm{S}_{\text {cond" }}\right.$ is measured from the slopes of the increase in phase III modified to include the $0-3$ lung turnovers and $S_{\text {acin"** }}$ " is phase III over the first breath of the washout, minus the contribution of $S_{\text {cond"). We hypothesised that these novel indices }}$

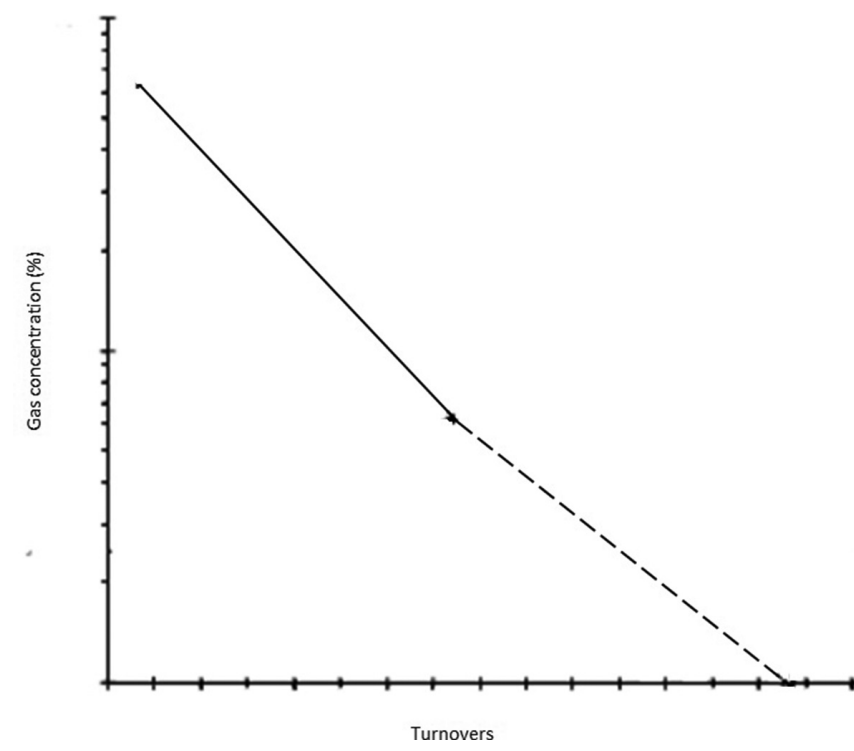

Abstract P208 Figure 1 Gas concentration (y axis, log scale) over the course of an MBW, plotted against turnovers ( $x$ axis). Solid line shows gradient of line from start to $\mathrm{LCl} / 2$, dotted line shows gradient of line from $\mathrm{LCl} / 2$ to full $\mathrm{LCl}$. Cury is expressed as the ratio of these two slopes. In health, slopes are similar and Cury is approaching zero, in disease, doffed slope is increasingly flat, giving an increased Cury value approaching 1 will differ in PCD compared to CF due to differences in small airways disease.

Methods 38 PCD (14 male, group mean (range) age 21.8 (7.259.1) years, FEV1 Z score $-3.18((-6-0.17))$ and CF (14 male, group mean (range) age $10.9(6.8-19.1)$ years, FEV1 Z score $2.72((-5.4-0.9))$ patients matched for P. aeruginosa status and 24 healthy controls recorded spirometry and MBW. LCI, Curv, Scond* and Sacin* were calculated.

Results There was no difference in LCI, FEV ${ }_{1}$ and Curv between the patient groups. LCI was correlated with $\mathrm{S}_{\text {cond" }}$ (CF $\mathrm{p}=0.0006, \mathrm{r}=0.5, \mathrm{PCD}, \mathrm{p}=0.03 \mathrm{r}=0.3), \mathrm{S}_{\text {acin* }}(\mathrm{CF} \mathrm{p}<$ $0.0001, \mathrm{r}=0.7, \mathrm{PCD} \mathrm{p}<0.0001, \mathrm{r}=0.6)$ and $\mathrm{S}_{\text {acin }}(\mathrm{CF} \mathrm{p}<$ $0.0001, r=0.7$, PCD $p=0.0003, r=0.5)$, whereas $S_{\text {cond }}$ was not. There was no difference in $S_{\text {acin }^{*}}$ * between the groups, but $\mathrm{S}_{\text {cond" }}$ was significantly lower in PCD, approaching that of healthy controls.

Conclusions Curv is similarly impaired in PCD and CF. $\mathrm{S}_{\text {cond* }}$ is nearly normal in PCD but not CF, supporting the hypothesis that there are differences in distal airway disease between these conditions. Finally, the results suggest that the new indices may be better discriminators between diseases in severe obstructive lung disease.

\section{P209 STANDARDISATION OF LUNG CLEARANCE INDEX IN A MULTICENTRE CLINICAL TRIAL}

DK Armstrong, KJ Bayfield, EWFW Alton, AC Boyd, S Cunningham, HI Elgmati, DR Gill, U Griesenbach, TE Higgins, SC Hyde, JA Innes, CJ Saunders, EJ Spearing, JC Davies. UK Cystic Fibrosis Gene Therapy Consortium (UKCFGTC), London, Oxford, Edinburgh, UK

\subsection{6/thoraxjnl-2014-206260.338}

Introduction Lung clearance index (LCI) is a sensitive and repeatable non-invasive measure of ventilation inhomogeneity derived from the multiple breath washout (MBW) technique. It is more sensitive to early lung disease than traditional lung function measurements. Before it can be adopted as a primary endpoint in multicentre trials, it must be demonstrated that it can be applied with minimal inter-operator variability. LCI is a major secondary outcome in our gene therapy multidose trial.

Aim To assess LCI achievability and intra- and inter-site agreement. Method 136 CF patients at two sites with $\mathrm{FEV}_{1}$ 50-90\% predicted were randomly allocated on a 1:1 basis to receive 12 monthly nebulised doses of active gene therapy product or placebo. LCI was performed in triplicate on seven occasions for each subject using a MBW technique completed on an Inno$\operatorname{cor}^{\mathrm{TM}}$ device using $0.2 \% \mathrm{SF}_{6}$. Stringent quality control criteria have been developed, including offset calculations and minimal acceptable differences between tests. LCI was calculated using

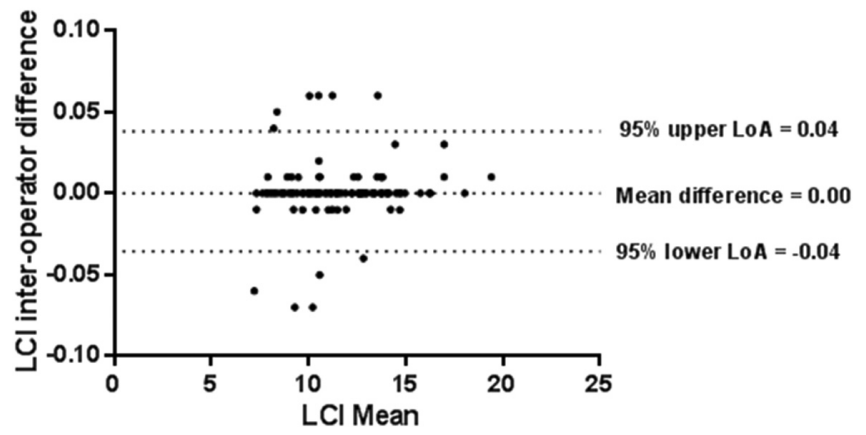

Abstract P209 Figure 1 Bland-Altman plot of LCI inter-operator difference 